Thorax (1961), 16, 190.

\title{
STAB WOUNDS PENETRATING THE LEFT ATRIUM
}

\author{
BY \\ MILROY PAUL \\ From the General Hospital, Colombo, Ceylon
}

(RECEIVED FOR PUBLICATION NOVEMBER 15,1960 )

A stab wound penetrating the left atrium (excluding the left auricle) would have to penetrate through other chambers of the heart or through the great arteries at their origin from the heart to reach the left atrium from the front of the chest. Such wounds would be fatal, the patient dying from profuse haemorrhage within a few minutes. A stab wound through the back of the chest could reach the left atrium in the narrow sulcus between the root of the left lung in front and the oesophagus and descending thoracic aorta behind, but placing a wound at this site without at the same time severing the vessels in the root of the left lung or the descending thoracic aorta would be an exceptional event, and the survival of a patient after a stab wound penetrating the left atrium would be dependent on it.

The present case of survival after a stab wound penetrating the left atrium appears to be the only one of its kind in the literature. It is reported not only on account of the rarity of its occurrence but also because of the unusual methods used to arrest the haemorrhage. Our experience in this case stimulated us to investigate by experimental surgery on animals the possibility of arresting haemorrhage from stab wounds of the heart without sutures, and these experiments confirmed the feasibility of this being done, even with stab wounds penetrating the ventricles of the heart.

\section{CAse Report}

M. L. S., a Singhalese man aged 35 years, was stabbed in the back at 6 p.m. on October 1, 1959. He was brought to a local hospital at 9 p.m. in a grave condition; he was cold and clammy and unable to make a statement. He had a stab wound half an inch long in the left eighth intercostal space in the posterior scapular line. This wound was sutured, and he was sent 22 miles to the General Hospital, Colombo.

$\mathrm{He}$ arrived at the General Hospital, Colombo, at 11.55 p.m. He was still cold and clammy, with a thready pulse at the wrists, temperature $97.8^{\circ}$, blood pressure $60 / 40 \mathrm{~mm}$. Hg. On this occasion there was no blood in the blood bank, and so he was given a slow drip of 2 pints of $5 \%$ dextrose which was followed by 4 pints of dextran throughout the night. At 7 a.m. the next day he was still alive, breathing quietly, with a pulse of 122 of good volume, blood pressure $100 / 70 \mathrm{~mm}$. $\mathrm{Hg}$, and warm extremities.

Although there was still no blood in the bank, an operation was decided on and begun at 8 a.m. By this time the pulse had again become small, although the extremities were warm. The left chest was opened through an intercostal incision in the eighth intercostal space. The left pleural cavity contained fluid blood and clots. In the outer surface of the lung underlying the stab wound of the chest wall there was a stab wound of the lung. The base of the left lung was adherent to the diaphragm. At this stage bright blood began to pour from behind the lung. The lung

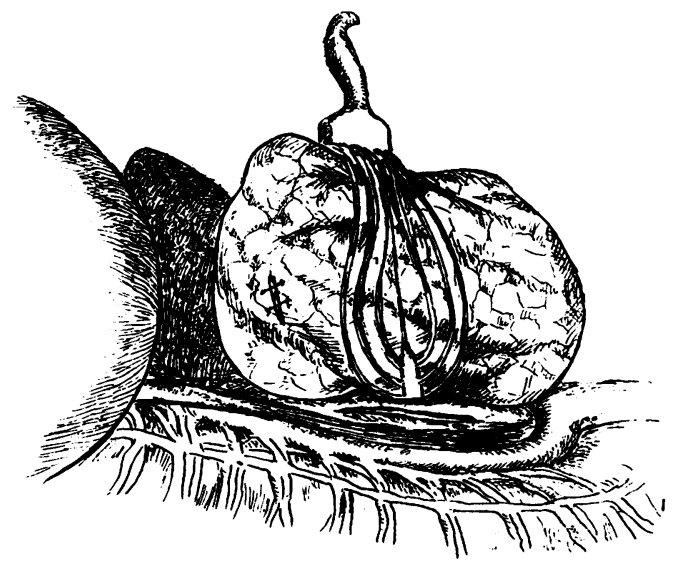

FIG. 1.-View at operation showing the position of the wound in the left atrium.

was mobilized by separating the adhesions to the diaphragm and it was retracted forwards. Bright red blood was escaping from a wound in the posterior mediastinum, but a gauze swab was pressed against it and arrested the bleeding. By now the pulse was imperceptible at the wrists. The gauze swab was maintained in position over the wound of the posterior mediastinum while an urgent call was sent for blood, which was brought in half an hour and a blood transfusion begun. The gauze plug in the mediastinum was then removed. The edges of the wound in the posterior mediastinum had sealed, and no blood escaped from the wound, which was $1 \frac{1}{2}$ in. long, 
behind the root of the left lung and in front of the descending thoracic aorta. Interrupted sutures were inserted into the wound and the chest incision was closed, after a tube had been placed draining the left pleural cavity to an under-water seal. The patient made an uninterrupted recovery and left hospital on October 17, 1959, with his wounds healed by first intention.

The stab in the left chest posteriorly had penetrated the lung and incised the left atrium to a length of $1 \frac{1}{2}$ inches. The incision into the left atrium was behind the root of the left lung, and here the pericardium is so tightly apposed against the wall of the left atrium that no blood had leaked into the pericardium, and firm pressure on the wound in the pericardium occluded the wound in the left atrium. The firm application of gauze for half an hour, which was necessitated by the peculiar circumstances of the case, demonstrated that gauze pressure had sealed this long wound effectively. Although sutures were used, these did no more than ensure that the wound would not reopen. Sealing is possibly effected by the deposition of platelets.

\section{Arrest of Haemorrhage by Pressure of a Gauze Swab on a Stab Wound of the Right VENTRICLE OF A DOG}

The dog was anaesthetized by intravenous nembutal, and respiration maintained through an intratracheal catheter with artificial ventilation. The left chest was opened through an intercostal incision. The lung and pericardium were exposed, and the pericardium opened. A stab was made into the right ventricle just in front of the intraventricular groove. Bright red blood spurted out in jets. A gauze swab on a haemostat was pressed over the stab wound. The bleeding was stopped. The gauze swab was maintained in position for five minutes, and it was then replaced by a gauze pack over the wound and against the chest wall and removed after 10 minutes. Blood began to ooze from the stab wound. The gauze pack was replaced over the wound for a further 10 minutes, and when this was removed there was a thin line of blood on the wound. The gauze pack held on a haemostat was reapplied for five minutes more. When the plug was removed the wound edges were sealed, and blood did not escape. The opening in the chest wall was closed.

The dog made a good recovery from the operation. He was standing up the next morning, and five days later was taken on a lead up and down three flights of stairs to the top of the Department of Physiology without suffering any discomfort. The animal has since had two litters uneventfully.

Dr. S. Y. D. C. Wickremasinghe, research assistant to the professor of surgery, was responsible for looking after this patient before, during, and after the operation, and he also took part in the experimental work on the dog. Fig. 1 was drawn by $\mathrm{Mr}$. A. S. Mahawatta, artist and photographer, University of Ceylon. 